Research Article

\title{
Experimental and Theoretical Studies of Eosin Y Dye as Corrosion Inhibitors for Carbon Steel in Perchloric Acid Solution
}

\author{
Tarik Attar1, 2,*, Abbes Benchadli², Boulanouar Messaoudi ${ }^{1,3}$, Naceur Benhadria ${ }^{1,4}$, \\ Esma Choukchou-Braham²
}

${ }^{1}$ Higher School of Applied Sciences of Tlemcen, BP 165, Bel Horizon, 13000 Tlemcen, Algeria. ${ }^{2}$ Laboratory of Toxicomed, University Abou Beker Belkaid Tlemcen, BP119, 13000 Tlemcen, Algeria. ${ }^{3}$ Laboratory of Applied Thermodynamics and Molecular Modeling, Department of Chemistry, University of Abou Bekr Belkaïd Tlemcen, B.P. 119, 13000 Tlemcen, Algeria.

${ }^{4}$ Laboratory of Inorganic Materials Chemistry and Application, Department of Materials Engineering, University of Science and Technology of Oran (USTO M.B.), BP 1505, El M'naouar, 31000 Oran, Algeria.

Received: 9th May 2020; Revised: 23rd May 2020; Accepted: 25th May 2020; Available online: $30^{\text {th }}$ July 2020; Published regularly: August 2020

\begin{abstract}
The adsorption behavior and the inhibition performance of Eosin Y Dye for carbon steel corrosion in 1 $\mathrm{M}$ perchloric acid solution have been carried using weight loss and scanning electron micrograph (SEM) techniques as well theoretical calculations based on density functional theory (DFT). The studied inhibitor concentrations were between $5 \times 10^{-5} \mathrm{M}$ and $5 \times 10^{-3} \mathrm{M}$. Results obtained revealed that Eosin $\mathrm{Y}$ is an effective inhibitor and its inhibition efficiency increases with increasing concentration to attain $96.91 \%$ at $5 \times 10^{-3} \mathrm{M}$ at $30^{\circ} \mathrm{C}$. Thermodynamic parameters such as adsorption heat, adsorption entropy and adsorption free energy were obtained from experimental data of the temperature studies of the inhibition process at five temperatures ranging from 20 to $60^{\circ} \mathrm{C}$. It was found that the adsorption of Eosin $\mathrm{Y}$ could prevent steel from weight loss and the adsorption accorded with the Langmuir adsorption isotherm. The free energy of adsorption showed that the corrosion inhibition takes place by spontaneous physicochemical adsorption of inhibitor molecules on the carbon steel surface. SEM and DFT studies confirm the adsorption of Eosin Y on carbon steel surface. Copyright (C) 2020 BCREC Group. All rights reserved
\end{abstract}

Keywords: Carbon steel; Eosin Y; Weight loss; DFT; Corrosion Inhibitor; perchloric solution

How to Cite: Attar, T., Benchadli, A., Messaoudi, B., Benhadria, N., Choukchou-Braham, E. (2020). Experimental and Theoretical Studies of Eosin Y Dye as Corrosion Inhibitors for Carbon Steel in Perchloric Acid Solution. Bulletin of Chemical Reaction Engineering \& Catalysis, 15(2), 454-464 (doi:10.9767/bcrec.15.2.7753.454-464)

Permalink/DOI: https://doi.org/10.9767/bcrec.15.2.7753.454-464

\section{Introduction}

Carbon steel has a large application in the production and/or designing of important engi-

* Corresponding Author.

Email: t.attar@essat-tlemcen.dz (T. Attar)

Telp: +213-66-2218567 neering components in the form of tools or machine parts due to its inherent remarkable properties [1]. Some of these components or machine tools are not protected when exposed to unfavorable environment during services. For example, the surface of either bare or coated parts tends to disintegrate, rust, corrode, and crack, result- 
ing economic collapse in terms of environmental pollution, safety, product losses, repair, and replacement [2]. These negative effects can be minimized or eliminated using diverse techniques to protect the surface of the metal from the aggressive environments. The employment of corrosion inhibitors, to keep metals and alloys against corrosion, has been considered to be the greatest practical method [3,4]. A corrosion inhibitor is a compound, when introduced or added in a little quantity to a corrosive environment regulates the rate of metal dissolution by producing a preventive barrier film, which in turn arrests the corrosive reaction from progressing [5,6]. Organic inhibitors mostly have heteroatoms, triple bonds or aromatic rings and the atoms as $\mathrm{O}, \mathrm{N}$, and $\mathrm{S}$, which are the active centers for the process of adsorption on the metal surface [7-9]. These atoms represent a higher basicity and electron density and thus act as corrosion inhibitor. The organic compounds react as an effective inhibitor is due to its ability to be adsorbed onto the metal surface. Some organic dyes have been used to confer multi-colour effects to anodised metal surfaces and the ability of such dyes to impart some corrosion protective effects presents a supplementary benefit. Dyes have long been applied in the coloring, paper industries, printing, plastics, leather, cosmetics, textile industry, pharmaceuticals, agri-food industries and the medical industry $[10,11]$.

Earlier studies by several researchers reported that some organic dyes are quite effective in retarding the corrosion of iron and steel in aggressive acid environments [12-30]. Thus, some work were evaluated the use of Azorubine, Sunset Yellow, Amaranth, Allura Red, Tartrazine, Fast Green, Nile Blue, Indigo Carmine, Red cabbage, Natural Kermes, Safranin, as corrosion inhibitors for mild steel in hydrochloric acid solutions [12-17], although, some dyes, as Congo red, Bismark brown, Malachite green and Naphthol, were also investigated for aluminum surface in hydrochloric acid [18-21]. Cresol red, Methyl violet, and Alizarin violet have been used as well for the corrosion inhibition of cold rolled steel in acidic solution [2224]. Additionally, Alizarin yellow, Bromophenol blue, Thiophene azo, Phtalocyanine Blue and Acid red GRE, have also been studied as corrosion inhibitors for carbon steel in acidic environments [25-30].

As a continuation of the work on the use of organic dyes as corrosion inhibitors in acidic solutions, we have probed its inhibiting action on the corrosion of carbon steel in $1 \mathrm{M} \mathrm{HClO}_{4}$. The effects of inhibitor concentration and tempera- ture on the performance and extent of adsorption of Eosin Y dye are also studied.

\section{Materials and Methods}

\subsection{Material Preparation}

Carbon steel samples used as test materials contain: C: $0.37 \%, \mathrm{Mn}: 0.68 \%, \mathrm{Cu}: 0.16 \%$, Cr: $0.077 \%$, Ni: $0.059 \%$, Si: $0.023 \%$, S: $0.016 \%$, Ti: $0.011 \%$, Co: $0.009 \%$ and the balance being Fe. Before proceeding to any test, the samples of carbon steel were mechanically abraded with different grades emery paper $(100,400,600$, 800,1000 and 1200). The weight loss measurements were carried out in the test solution of 1 $\mathrm{M}$ perchloric acid, which was prepared by dilution of 70-72 \% $\mathrm{HClO}_{4}$ (Sigma-Aldrich) with double deionized water. Each sample was weighed by an electronic balance $( \pm 0.0001 \mathrm{~g})$ and then placed in the acid solution $(50 \mathrm{~mL})$.

\subsection{Weight Loss Method}

Weight loss measurements were performed on the carbon steel samples with a rectangular form in one molar perchloric acid medium with and without addition of different concentrations of Eosin Y Dye. The duration of the immersion was $2 \mathrm{~h}$ at the temperature range from 293 to $333 \mathrm{~K}$. After immersion, the surface of the specimen was cleaned by double distilled water followed rinsing with acetone and the sample was weighed again in order to calculate inhibition efficiency (IE\%) the corrosion rate $\left(C_{R}\right)$. All measurements were done in triplicate, and the average value of the weight loss was noted. For each experiment, a freshly prepared solution was used, and the solution temperature was thermostatically controlled at a desired value.

The following equations were used to calculate the corrosion rate $\left(C_{R}\right)$, the inhibition efficiencies $(I E \%)$ and the surface coverage $(\theta)$ [31]:

$$
\begin{aligned}
& C_{R}=\frac{\Delta W}{S t} \\
& I E \%=\frac{100 \times\left(C_{R}^{\prime}-C_{R}\right)}{C_{R}^{\prime}} \\
& \theta=\frac{I E \%}{100}
\end{aligned}
$$

where, $\Delta W$ is the weight loss (g), $S$ is the total area of the specimen $\left(\mathrm{cm}^{2}\right), t$ is the exposure time (h), $C_{R}^{\prime}$ and $C_{R}$ are respectively, the corrosion rates of carbon steel samples in the absence and presence of inhibitor $\left(\mathrm{g} . \mathrm{cm}^{-2} \cdot \mathrm{h}^{-1}\right)$, respectively, $\theta$ is the surface coverage. The results 
of corrosion tests in $1 \mathrm{M} \mathrm{HClO}_{4}$ at $303 \mathrm{~K}$ for the corrosion of carbon steel in presence of different concentrations of Eosin $\mathrm{Y}$ and various immersed time are presented in Table 1.

\subsection{Quantum Chemical Computation}

Geometry optimization of both inhibitor molecules and quantum chemical calculations were carried out in the Gaussian-09 program using DFT at B3LYP/6-31G* level of theory. In recent years, the DFT methods have become very popular because they can achieve the same exactitude to other methods in less time and they are less expensive from a computational point of view.

The HOMO energy is related to the ionization potential $(I)$, whereas the LUMO energy is linked to the electron affinity $(A)$, as shown below [32].

$$
A=-E_{\text {LUMO }}, I=-E_{\text {Номо }}
$$

The energy gap $(\Delta E)$ and the global electronic chemical potential $(\mu)$ are determined as follow [33].

$$
\begin{aligned}
& \Delta E=E_{\text {LUМО }}-E_{\text {Номо }} \\
& \mu=\frac{1}{2} \times\left(E_{\text {LUMO }}+E_{\text {НОМО }}\right)
\end{aligned}
$$

The electronegativity $(\chi)$ and the global hardness $(\eta)$ can be calculated as a function of $I$ and $A$ by equations 7 and 8 [34].

$$
\begin{aligned}
& \chi=\frac{1}{2} \times(I+A) \\
& \eta=\frac{1}{2} \times(I-A)
\end{aligned}
$$

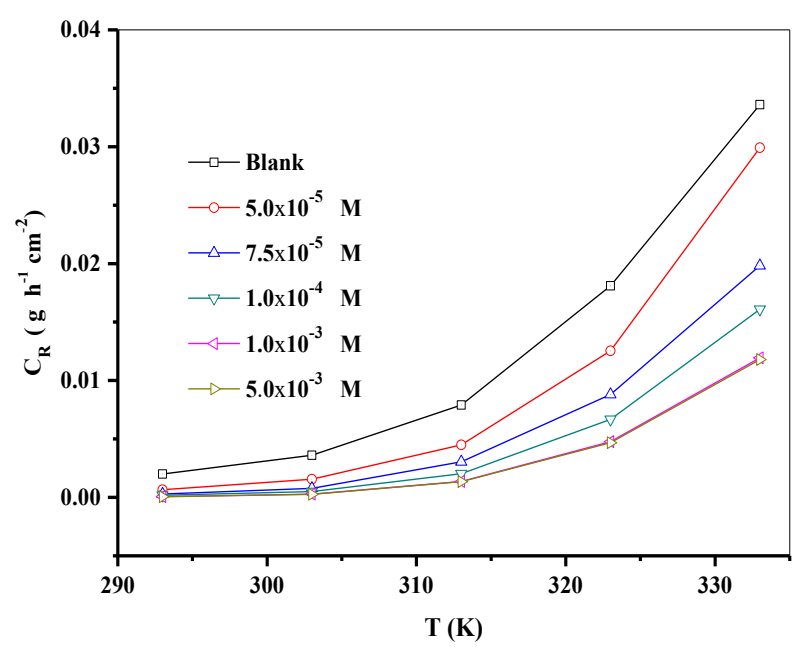

Figure 1. Variation of corrosion rate with the concentrations of Eosin $\mathrm{Y}$ for carbon steel at different temperatures.
Global softness $(\sigma)$ demonstrates the capacity of an atom or group of atoms to receive electrons and it is estimated by using the equation [35].

$$
\sigma=\frac{1}{\eta}
$$

The electrophilicity index is calculated as in Equation (10) [36,37].

$$
\omega=\frac{\mu^{2}}{2 \eta}
$$

\section{Results and Discussion}

3.1 Effect of Immersion Time and Concentration on Corrosion Rates and Inhibition Efficiency

The weight loss measurements were studied in $1 \mathrm{M} \mathrm{HClO}_{4}$ in the absence and presence of different concentration of Eosin $\mathrm{Y}$ of $5 \times 10^{-5}$ to $5 \times 10^{-3} \mathrm{M}$ for a period ranging from $30 \mathrm{~min}$ to 24 $\mathrm{h}$ immersion time at temperature $303 \mathrm{~K}$. According to Table 1, it was found that the inhibition efficiency of Eosin Y increased up to $96.91 \%$ at higher concentration which is $5 \times 10^{-3}$ $\mathrm{M}$ at 2 hours immersion time. Therefore, it can be concluded that the inhibition efficiency increased with increasing of immersion time due to the stability of the adsorbed layer on the carbon steel surface until 2 hours of immersion at different concentrations of inhibitor. The increasing inhibition efficiency with increasing immersion time is due to the increase in the surface coverage with time until to two hours immersion then it decreases after this time. It was found that when the concentration of Eosin $\mathrm{Y}$ inhibitor increases the corrosion rates decreases. From Table 1, it can be seen that the inhibition efficiencies increase with the increase in Eosin Y concentration. The surface coverage, $\theta$ for different concentrations of inhibitors in $1.0 \mathrm{M} \mathrm{HClO}_{4}$, was calculated and it was found that Eosin Y proficiently covers the surface of carbon steel.

\subsection{Temperature Effect}

The temperature is an important factor in the metal dissolution process, the effect of temperature upon the corrosion and corrosion inhibition of carbon steel in perchloric acid, in the absence and presence of various concentrations of the Eosin Y inhibitor was investigated by weight loss measurements after immersion at 293 to $333 \mathrm{~K}$ for two hours. In the Figure 1, the observed results show an increase in corrosion 
Table 1. Corrosion rate and inhibition efficiency for carbon steel in $1 \mathrm{M} \mathrm{HClO}_{4}$ in the absence and presence of Eosin Y at $303 \mathrm{~K}$.

\begin{tabular}{|c|c|c|c|c|}
\hline $\begin{array}{l}\text { Inhibitor concentration } \\
(\mathrm{M})\end{array}$ & $\begin{array}{l}\text { Time } \\
(\mathrm{h})\end{array}$ & $\begin{array}{l}\text { Corrosion rate } \\
\left(\mathrm{g} \cdot \mathrm{cm}^{-2} \cdot \mathrm{h}^{-1}\right)\end{array}$ & $\begin{array}{l}\mathrm{IE} \\
(\%)\end{array}$ & $\begin{array}{c}\text { Surface coverage } \\
\theta\end{array}$ \\
\hline \multirow{7}{*}{0} & 0.5 & $1.00 \times 10^{-3}$ & - & \\
\hline & 1 & $2.00 \times 10^{-3}$ & - & \\
\hline & 2 & $3.60 \times 10^{-3}$ & - & \\
\hline & 3 & $3.99 \times 10^{-3}$ & - & \\
\hline & 4 & $4.39 \times 10^{-3}$ & - & \\
\hline & 6 & $5.51 \times 10^{-3}$ & - & \\
\hline & 24 & $6.49 \times 10^{-3}$ & & \\
\hline \multirow{7}{*}{$5 \times 10^{-5}$} & 0.5 & $9.09 \times 10^{-4}$ & 9.06 & 0.09 \\
\hline & 1 & $8.21 \times 10^{-4}$ & 58.93 & 0.58 \\
\hline & 2 & $1.28 \times 10^{-3}$ & 64.44 & 0.64 \\
\hline & 3 & $1.54 \times 10^{-3}$ & 61.40 & 0.61 \\
\hline & 4 & $1.90 \times 10^{-3}$ & 56.72 & 0.56 \\
\hline & 6 & $2.70 \times 10^{-3}$ & 50.99 & 0.50 \\
\hline & 24 & $3.42 \times 10^{-3}$ & 47.30 & 0.47 \\
\hline \multirow{7}{*}{$7.5 \times 10^{-5}$} & 0.5 & $8.96 \times 10^{-4}$ & 10.39 & 0.10 \\
\hline & 1 & $6.44 \times 10^{-4}$ & 67.79 & 0.67 \\
\hline & 2 & $9.48 \times 10^{-4}$ & 73.66 & 0.73 \\
\hline & 3 & $1.52 \times 10^{-3}$ & 61.90 & 0.61 \\
\hline & 4 & $1.84 \times 10^{-3}$ & 58.08 & 0.58 \\
\hline & 6 & $2.58 \times 10^{-3}$ & 53.17 & 0.53 \\
\hline & 24 & $3.30 \times 10^{-3}$ & 49.15 & 0.49 \\
\hline \multirow{7}{*}{$1 \times 10^{-4}$} & 0.5 & $8.49 \times 10^{-4}$ & 15.10 & 0.15 \\
\hline & 1 & $5.77 \times 10^{-4}$ & 71.15 & 0.71 \\
\hline & 2 & $6.19 \times 10^{-4}$ & 82.80 & 0.82 \\
\hline & 3 & $1.28 \times 10^{-3}$ & 67.91 & 0.67 \\
\hline & 4 & $1.58 \times 10^{-3}$ & 64.01 & 0.64 \\
\hline & 6 & $2.23 \times 10^{-3}$ & 59.52 & 0.59 \\
\hline & 24 & $2.86 \times 10^{-3}$ & 55.93 & 0.55 \\
\hline \multirow{7}{*}{$1 \times 10^{-3}$} & 0.5 & $7.71 \times 10^{-4}$ & 22.90 & 0.22 \\
\hline & 1 & $3.33 \times 10^{-4}$ & 83.35 & 0.83 \\
\hline & 2 & $2.77 \times 10^{-4}$ & 92.30 & 0.92 \\
\hline & 3 & $7.33 \times 10^{-4}$ & 81.62 & 0.81 \\
\hline & 4 & $9.18 \times 10^{-4}$ & 79.08 & 0.79 \\
\hline & 6 & $1.29 \times 10^{-3}$ & 76.58 & 0.76 \\
\hline & 24 & $1.96 \times 10^{-3}$ & 69.79 & 0.69 \\
\hline \multirow{7}{*}{$5 \times 10^{-3}$} & 0.5 & $7.06 \times 10^{-4}$ & 29.40 & 0.29 \\
\hline & 1 & $2.37 \times 10^{-4}$ & 88.15 & 0.88 \\
\hline & 2 & $1.11 \times 10^{-4}$ & 96.91 & 0.96 \\
\hline & 3 & $5.74 \times 10^{-4}$ & 85.61 & 0.85 \\
\hline & 4 & $7.97 \times 10^{-4}$ & 81.84 & 0.81 \\
\hline & 6 & $1.24 \times 10^{-3}$ & 77.49 & 0.77 \\
\hline & 24 & $1.77 \times 10^{-3}$ & 72.72 & 0.72 \\
\hline
\end{tabular}


rate with increasing temperature both in the presence and absence of inhibitor. This increase in corrosion rate can be explained by desorption of the adsorbed Eosin Y molecules from the carbon steel surface at higher temperature. The high rate of dissolution of carbon steel in perchloric acid solution observed at elevated temperature could be attributed to more dissolution energy effect acquired by the corrosive agent within the aggressive medium.

\subsection{Adsorption Considerations}

The protective layer on the metal surface resulting from the adsorption of the inhibitor on the surface during acid induced corrosion regulates the corrosive effect on the metal surface by either homogeneous or heterogeneous layer adsorption [38]. The adsorption isotherm explains the interaction between inhibitor molecules and the carbon steel surface. Corrosion inhibition of carbon steel in the presence of inhibitor has been studied to the adsorption on the carbon steel surface, and this was generally confirmed from the fit of the experimental data to different adsorption isotherms.

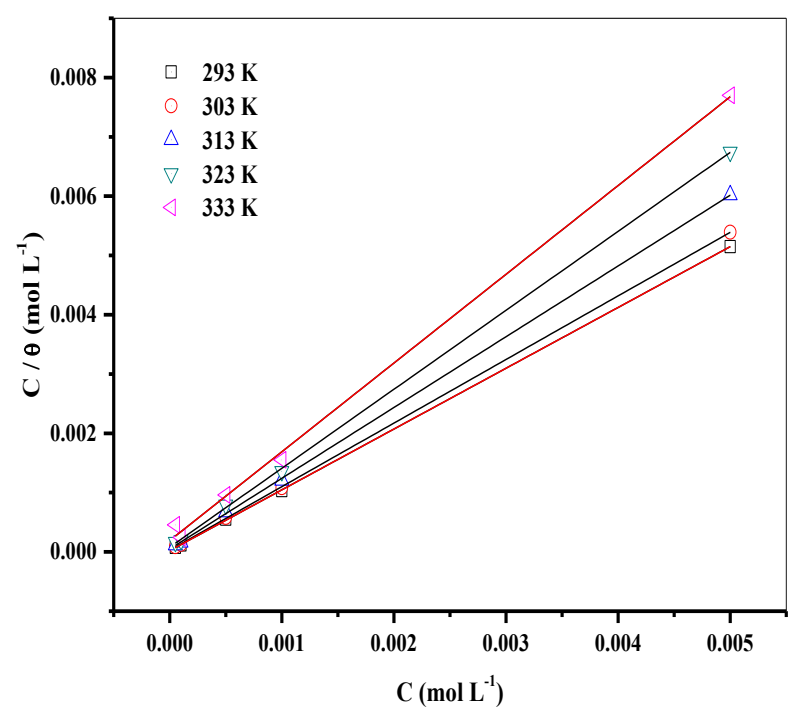

Figure 2. Langmuir isotherm for the adsorption of Eosin $\mathrm{Y}$ on carbon steel in $1 \mathrm{M} \mathrm{HClO}_{4}$.
The plots of $C / \theta$ versus $C$ yield a straight line with approximately unit slope, indicating that the inhibitor under study follows the Langmuir adsorption isotherm (Figure 2). The $K_{a d s}$ values can be calculated from the intercept lines on the $C / \theta$-axis. According to this isotherm, $\theta$ is related to $C$ by this equation.

$$
\frac{C}{\theta}=\frac{1}{K_{a d s}}+C
$$

where, $K_{a d s}$ is the equilibrium constant of the adsorption reaction and $\theta$ is surface coverage value.

The results of the present studies at $293 \mathrm{~K}$ to $333 \mathrm{~K}$ indicated that the mechanism of adsorption of inhibitor onto the carbon steel surface is better obeyed by the Langmuir adsorption isotherm (Table 2). The free energy of the adsorption of inhibitor on carbon steel surface can be evaluated with the following equation $[39,40]$ :

$$
\Delta G_{a d s}=-R T \ln \left(55.5 K_{a d s}\right)
$$

where $R$ is the gas constant $\left(\mathrm{J} . \mathrm{mol}^{-1} \cdot \mathrm{K}^{-1}\right)$ and $T$ is the absolute temperature $(\mathrm{K}) .55 .5$ is the concentration of water in solution (mol.L-1).

The high value of the equilibrium constant at lower temperature reflects the high adsorption ability of the Eosin Y on carbon steel surface [41]. The value of adsorption enthalpy is 44.06 KJ.mol-1 for Eosin Y, confirming the exothermic behavior of adsorption on the carbon steel surface. The negative value of enthalpy of adsorption reflects the exothermic nature of the adsorption of Eosin Y on the carbon steel surface in the perchloric acid solution.

The negative values of free energy for Eosin

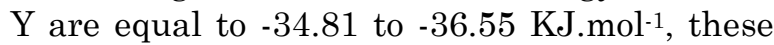
negative signs indicate the stability of the adsorbed layer on the carbon steel surface and the spontaneity of the adsorption process while positive signs symbolize a non-spontaneous adsorption process. This result indicates that the adsorption process of this inhibitor involves both physisorption and chemisorption mechanisms.

Table 2. Thermodynamic parameters for the adsorption of Eosin $\mathrm{Y}$ in $1 \mathrm{M} \mathrm{HClO}_{4}$ solution on carbon

\begin{tabular}{|c|c|c|c|c|c|}
\hline $\mathrm{T}(\mathrm{K})$ & $\mathrm{R}^{2}$ & $\begin{array}{l}10^{3} \times \mathrm{K}_{\mathrm{ads}} \\
\left(\mathrm{L} . \mathrm{mol}^{-1}\right)\end{array}$ & $\begin{array}{c}\Delta H_{a d s} \\
\left(\mathrm{KJ} \mathrm{mol}^{-1}\right)\end{array}$ & $\begin{array}{c}\Delta S_{a d s} \\
\left(\mathrm{~J} . \mathrm{mol}^{-1} \cdot \mathrm{K}^{-1}\right)\end{array}$ & $\begin{array}{c}\Delta G_{a d s} \\
\left(\mathrm{KJ} . \mathrm{mol}^{-1}\right)\end{array}$ \\
\hline 293 & 0.999 & 47.74 & & -27.43 & -36.02 \\
\hline 303 & 0.999 & 36.06 & & -24.81 & -36.55 \\
\hline 313 & 0.999 & 20.69 & -44.06 & -24.77 & -36.31 \\
\hline 323 & 0.999 & 12.68 & & -24.48 & -36.15 \\
\hline 333 & 0.997 & 5.21 & & -27.78 & -34.81 \\
\hline
\end{tabular}
steel at different temperatures. 
Generally, physisorption is the electrostatic interaction between the charged molecules against the charged metal surface. Values of $\Delta G_{\text {ads }}$ until $-20 \mathrm{KJ}^{\mathrm{mol}} \mathrm{mol}^{-1}$ are consistent with the physical adsorption while those lower than -40 KJ.mol-1 are correlated with the chemisorption [42].

\subsection{Thermodynamic Parameter}

The increase in energy of activation for corrosion process in inhibitor solution further interpreted as physical adsorption of inhibitor species on carbon steel surface. The Arrhenius equation can be employed with success to show the action of temperature on the inhibition performance of studied compounds. It is represented by the Equation (13) [43].

$$
C_{R}=A+\exp \left(-E_{a} / R T\right)
$$

where $C_{R}$ is the corrosion rate of carbon steel, $A$ is the Arrhenius pre-exponential factor, $E_{a}$ (KJ.mol-1) is the activation energy, $R$ is the gas

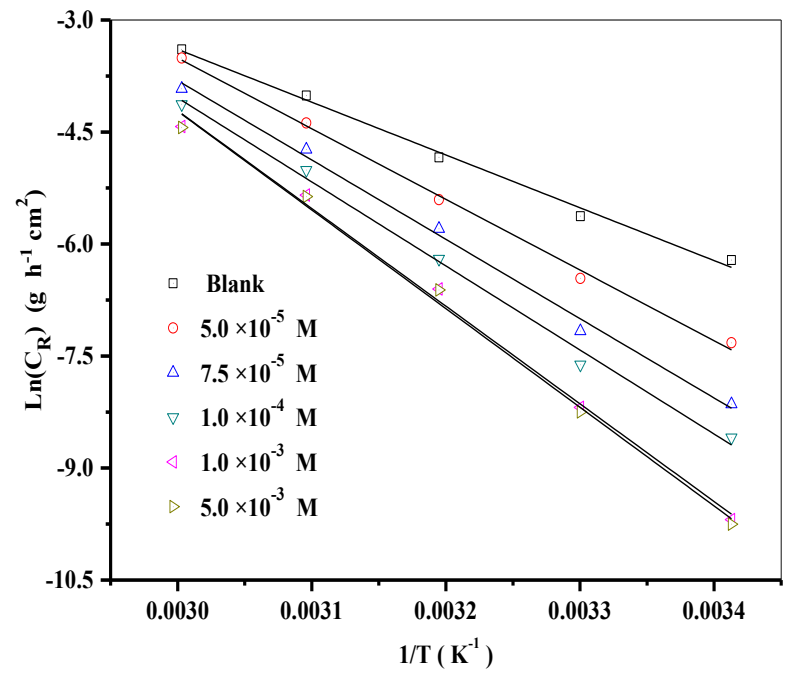

Figure 3. Arrhenius plots for carbon steel corrosion in $1 \mathrm{M} \mathrm{HClO}_{4}$ without and with different concentrations of Eosin Y. constant (8.314 J.mol-1. $\mathrm{K}^{-1}$ ) and $T$ is the temperature $(\mathrm{K})$. The values of $E_{a}$ (Table 3 ) for carbon steel in $1 \mathrm{M} \mathrm{HClO}_{4}$ without and with different concentrations of inhibitors were obtained from the slope of the plot of $\ln \left(C_{R}\right)$ versus $1 / T$ (Figure 3 ).

The values of enthalpy of activation $\left(\Delta H_{a}\right)$, entropy of activation $\left(\Delta S_{a}\right)$ and free-energy $\left(\Delta G_{a}\right)$ can be calculated by Equations (14) and (15) $[44,45]$.

$$
\begin{aligned}
& \ln \left(\frac{C_{R}}{T}\right)=\left[\ln \left(\frac{R}{N h}\right)+\frac{\Delta S_{a}}{R}\right]-\frac{\Delta H_{a}}{R T} \\
& \Delta G_{a}=\Delta H_{a}+T \Delta S_{a}
\end{aligned}
$$

where $h$ is plank's constant, $N$ is Avogadro number $R$ is the gas constant. A plot of $\ln \left(C_{R} / T\right)$ vs $1 / T$ gave a straight line with slope of ($\left.\Delta H_{a} / R\right)$ and intercept of $\left[\ln (R / N h)+\left(\Delta S_{a} / R\right)\right]$ from which the values of $\Delta H_{a}$ and $\Delta S_{a}$ can be calculated (Figure 4).

These values of $\Delta H_{a}, \Delta S_{a}$ and $\Delta G_{a}$ are tabulated in Table 3 . Table 3 revealed that $E_{a}$ and $\Delta H_{a}$ values increase in the presence of Eosin Y,

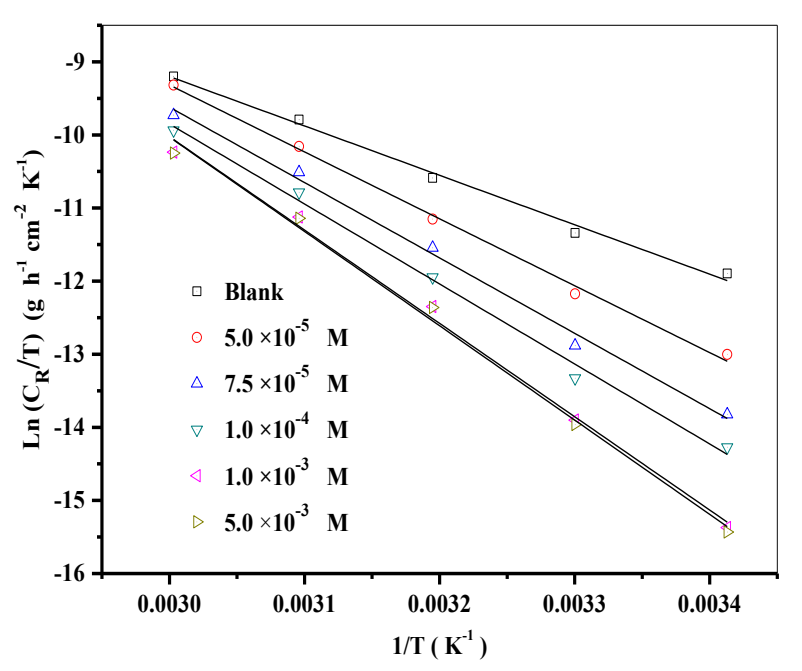

Figure 4. Transition state plots for carbon steel corrosion in $1 \mathrm{M} \mathrm{HClO}_{4}$ without and with different concentrations of Eosin Y.

Table 3. The thermodynamic activation functions of carbon steel dissolution in $1 \mathrm{M} \mathrm{HClO}_{4}$ in the absence and presence of different concentrations of Eosin Y by applying Arrhenius and transition state plots.

\begin{tabular}{cccccc}
\hline$C_{\text {Inh }}(\mathrm{M})$ & $E_{a}\left(\mathrm{KJ} . \mathrm{mol}^{-1}\right)$ & $\mathrm{R}^{2}$ & $\Delta H_{a}\left(\mathrm{KJ} . \mathrm{mol}^{-1}\right)$ & $\Delta S_{a}\left(\mathrm{~J} . \mathrm{mol}^{-1} \cdot \mathrm{K}^{-1}\right)$ & $\Delta G_{a}(303 \mathrm{~K})\left(\mathrm{KJ} . \mathrm{mol}^{-1}\right)$ \\
\hline 0 & 58.79 & 0.991 & 56.20 & -105.43 & 88.14 \\
$5 \times 10^{-5}$ & 78.69 & 0.996 & 76.09 & -46.71 & 90.24 \\
$7.5 \times 10^{-5}$ & 88.33 & 0.993 & 85.73 & -20.30 & 91.88 \\
$1 \times 10^{-4}$ & 93.57 & 0.993 & 90.98 & -6.48 & 92.94 \\
$1 \times 10^{-3}$ & 108.75 & 0.993 & 106.15 & 37.59 & 94.76 \\
$5 . \times 10^{-3}$ & 109.86 & 0.993 & 107.27 & 40.96 & 94.86 \\
\hline
\end{tabular}


indicating a higher protection efficiency [46]. The lower value of apparent activation energy of corrosion process in the presence of the inhibitor when compared to that in absence of inhibitor is attributed to its chemisorption adsorption, its physisorption is pronounced in the opposite case. In this work, $E_{a}$ of inhibited solutions is higher than that of the uninhibited solution indicating a physical mode of adsorption. The positive values of $\Delta H_{a}$ indicate that the formation of the activated complex is an endothermic process [47]. The high negative value of entropy in the absence of inhibitor involves that the activated complex is the rate-determining step, rather than the dissociation step.

While in the presence of the inhibitor, the value of entropy increases, this is generally explained as an increase in disorder as the reactants are converted to the activated complexes. The shift towards positive value of entropies (from $1 \times 10^{-3} \mathrm{M}$ ) imply that the activated complex in the rate determining step represents dissociation rather than association, meaning that disordering increases on going from reactants to the activated complex. The positive value of activation free energy, meaning nonspontaneous corrosion reaction, increases with increasing concentration of inhibitor.

\subsection{Quantum Chemical Calculations}

The electronic structure of the Eosin $\mathrm{Y}$ was elucidated using the B3LYP/6-31G* level of theory. The highest occupied molecular orbital (HOMO) and lowest unoccupied molecular or- bital (LUMO) studied for Eosin Y are showed in Figure 5. The calculations of global reactivity indices of the inhibitors such as the energy of the highest occupied ( $\left.E_{\text {номо }}\right)$ and the lowest unoccupied $\left(E_{L U M O}\right)$ molecular orbitals, energy gap $(\Delta E)$, global electronic chemical potential $(\mu)$, hardness $(\eta)$, electrophilicity index $(\omega)$, softness $(\sigma)$ and the fraction of electron transfer $(\Delta N)$ from inhibitors to carbon steel were also calculated and discussed with inhibition efficiencies. The parameters named above are given in Table 4 . The energy gap value $(2.98 \mathrm{eV})$ indicates that Eosin $\mathrm{Y}$ is very reactive and can be adsorbed on steel surface, thus it can be considered as an efficient corrosion inhibitor. The $\Delta N$ value is correlated with the inhibition effectiveness, resulting from electron donation. If the fractions of electrons transferred values are lower than $3.6 \mathrm{eV}$, the inhibition efficiency increases with increasing electron-donating capacity at the metal surface [48].

In this study, the charge transfer is of the order of $1.60 \mathrm{eV}$ shows that the Eosin Y inhibitor is a strong electron donor power. A high electrophilicity $(\omega)$ value characterizes a good electrophile while a small electrophilicity value describes a good nucleophile, this index is helpful for the prediction of the direction of corrosion. Generally, whenever the softness index $(\sigma)$ is higher means that the adsorption is occurring [49]. The chemical hardness $(\eta)$ is an important quantum chemical that provides an estimation of corrosion inhibition efficiencies of molecules [50].
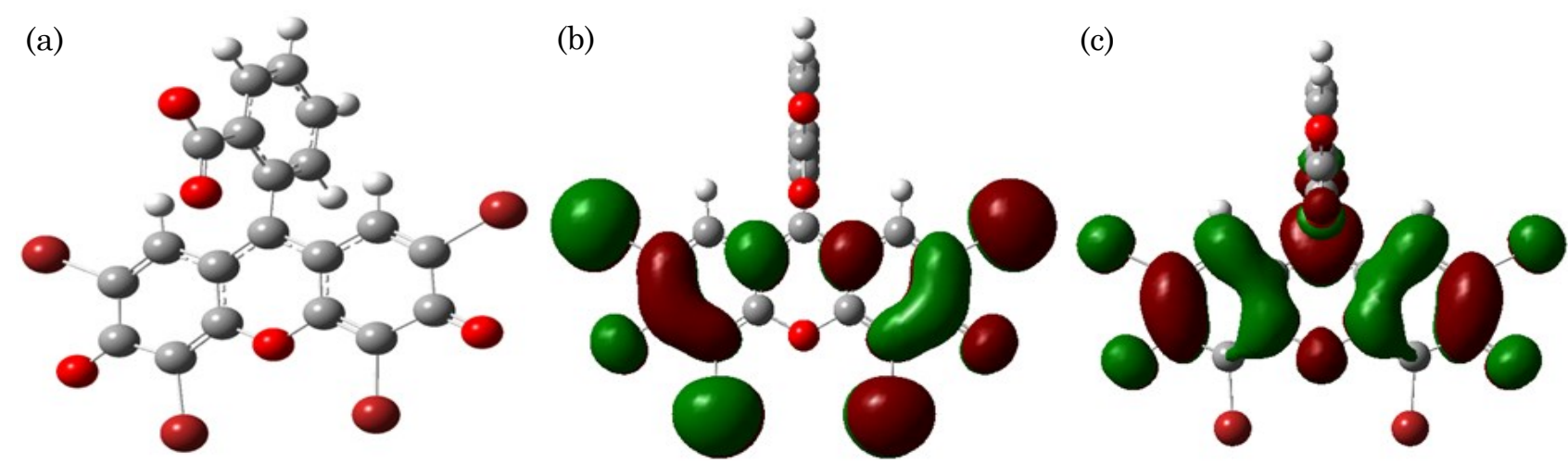

Figure 5. (a) Optimized structure, (b) HOMO and (c) LUMO orbitals for Eosin Y molecule using DFT approach.

Table 4. HOMO and LUMO energies, global reactivity indices $\mu, \eta, \sigma, \omega, \Delta E$ and $\Delta N$, for Eosin Y compound at B3LYP/6-31G* level of theory.

\begin{tabular}{ccccccccc}
\hline Substrate & $\begin{array}{c}E_{\text {НОMO }} \\
(\mathrm{eV})\end{array}$ & $\begin{array}{c}E_{\text {LUMO }} \\
(\mathrm{eV})\end{array}$ & $\begin{array}{c}\mu \\
(\mathrm{eV})\end{array}$ & $\begin{array}{c}\eta \\
(\mathrm{eV})\end{array}$ & $\begin{array}{c}\sigma \\
\left(\mathrm{eV}^{-1}\right)\end{array}$ & $\begin{array}{c}\omega \\
(\mathrm{eV})\end{array}$ & $\begin{array}{c}\Delta E \\
(\mathrm{eV})\end{array}$ & $\begin{array}{c}\Delta N \\
(\mathrm{eV})\end{array}$ \\
\hline Eosin Y & 0.35 & 3.33 & 1.84 & 2.74 & 0.36 & 0.62 & 2.98 & 1.6 \\
\hline
\end{tabular}




\subsection{Scanning Electron Microscopy (SEM)}

Scanning electron microscopy was probed to study the carbon steel specimen surface morphology. Figure 6 shows the SEM images of carbon steel specimens immersed to the uninhibited, inhibited acid media (for $24 \mathrm{~h}$ ) and polished surface. The polished carbon steel electrode surface before immersion was uniform (Figure 6a). After immersion time in corrosive attack, the surface was strongly deteriorated due to corrosion, this consequently initiates pitting or crevice corrosion, which is more pronounced for the steel surface in the absence of inhibitor as revealed from the large pit depth in (Figure 6b) [51]. In the presence of Eosin Y, thin film onto the carbon steel surface were formed as shown in Figure 6c. it is marked that there is a protective layer adsorbed onto the carbon steel surface which is responsible for corrosion inhibition.
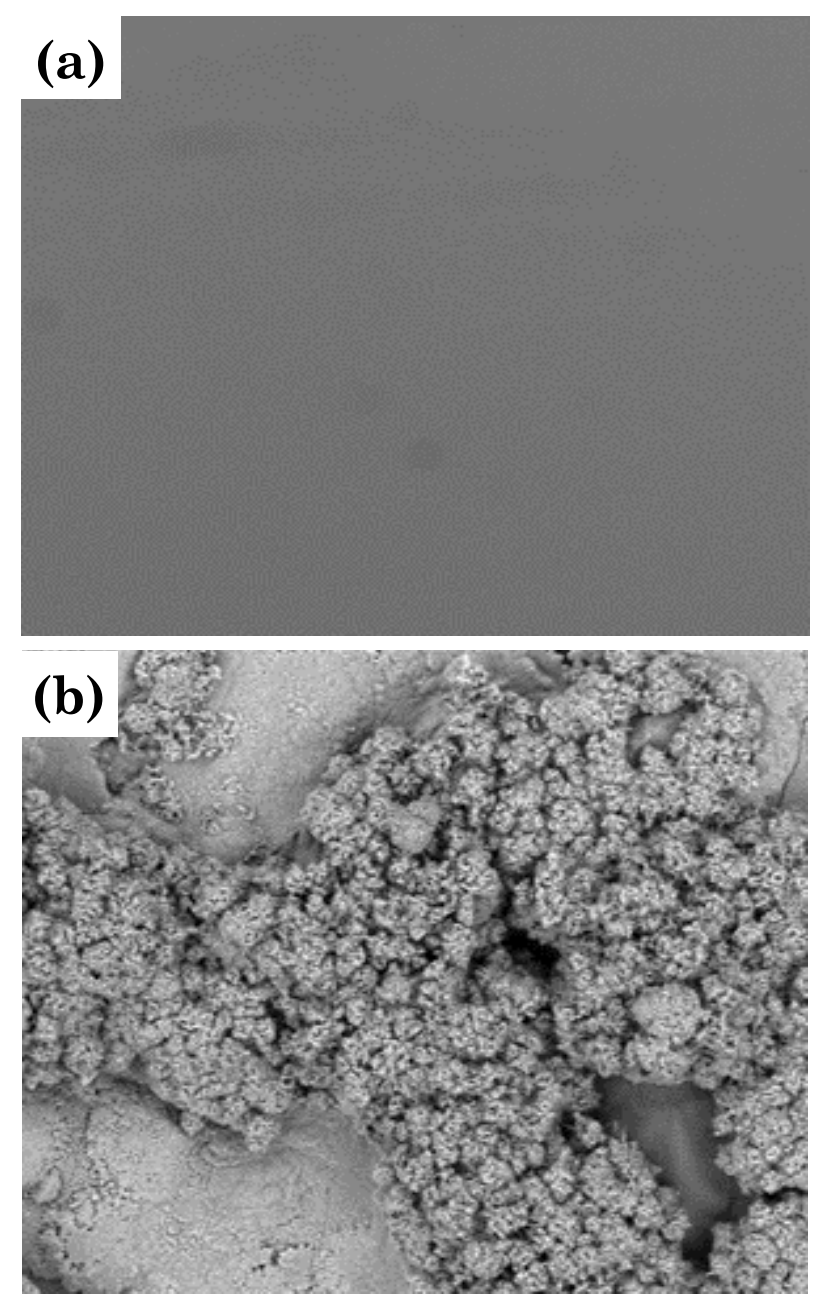

\section{Conclusion}

The obtained results show that Eosin Y dye acts as an excellent effective inhibitor for the corrosion of carbon steel in $1 \mathrm{M} \mathrm{HClO}_{4}$ solution. The increase in the inhibitor concentration decreases the corrosion rate while the increase in temperature leads to an increase in the corrosion rate. The inhibition efficiency increases with the increase in the concentration of Eosin Y dye. The adsorption of Eosin Y on the carbon steel surface follows the Langmuir adsorption isotherm. The values of thermodynamic parameters show that the adsorption process is a physicochemical adsorption process. The corrosion inhibition ability of Eosin Y has been confirmed via both scanning electron microscopy and quantum chemical calculations.

\section{Acknowledgments}

The researcher team would like to express their thanks to the Ministry of Higher Education and Scientific Research of the Algerian Government and Higher School of Applied Sciences for their fruitful support.

\section{References}

[1] Uranga, P., Shang, C., Senuma, T., Yang, JR., Guo, A-M., Moharbacher, H. (2014). Molybdenum alloying in highperformance flat-rolled steel grades. $A d v$. Manuf., 8, 15-34. DOI: 10.1007/s40436-01900285-y.

[2] David, W.H., Carlos, A.A. (2012). Exfoliation Corrosion and Pitting Corrosion and Their Role in Fatigue Predictive Modeling: State-ofthe-Art Review. Int. J. Aerospace. Eng., 2012, 1-29. DOI: $10.1155 / 2012 / 191879$.

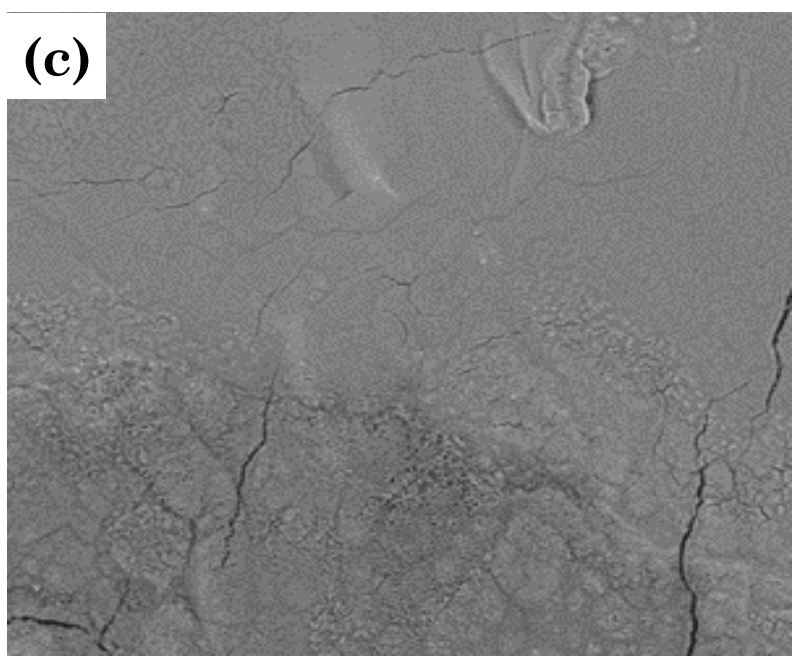

Figure 6. SEM images of carbon steel samples. (a) before immersion, (b) after immersion in $1 \mathrm{M}$ $\mathrm{HClO}_{4}$, (c) after immersion with $1 \times 10^{-3} \mathrm{M}$ of Eosin Y. 
[3] Rahal, H.T., Abdel-Gaber, A.M., Younes, G.O. (2016). Inhibition of steel corrosion in nitric acid by sulfur containing compounds. Chem. Eng. Commun., 203, 435-445. DOI: 10.1080/00986445.2015.1017636.

[4] Mohammadinejad, F., Ali Hosseini, S.M., Zandi, M.S., Bahrami, M.J., Golshani, Z. (2020). Metoprolol: New and Efficient Corrosion Inhibitor for Mild Steel in Hydrochloric and Sulfuric Acid Solutions. Acta Chim. Slov., 67, 2020, 1-10. DOI: 10.17344/acsi.2019.5301.

[5] Attar, T., Larabi, L., Harek, Y. (2014). The Inhibition effect of potassium iodide on the corrosion of pure iron in sulfuric acid. $A d v$. Chem., 2014, 1-5. DOI: 10.1155/2014/827514.

[6] Attar, T., Benchadli, A., Choukchou-Braham, E. (2019). Corrosion inhibition of carbon steel in perchloric acid by potassium iodide. Inter. J. Adv. Chem., 7, 35-41. DOI: 10.14419/ijac.v7i1.19651.

[7] Xhanari, K., Finšgar, M., Hrnčič, M.K, Maver, U., Knez, ž., Seitib, B. (2017). Green corrosion inhibitors for aluminium and its alloys: a review. RSC Advances., 7, 27299-27330. DOI: 10.1039/C7RA03944A.

[8] Ko, X., Sharma, S. (2017). Adsorption and self-assembly of surfactants on metal-water interfaces. J. Phys. Chem. B. 121, 1036410370. DOI: 10.1021/acs.jpcb.7b09297.

[9] Al-Moghrabi, R.S., Abdel-Gaber, A.M., Rahal, H.T. (2019). Corrosion Inhibition of Mild Steel in Hydrochloric and Nitric Acid Solutions Using Willow Leaf Extract. Prot. Met. Phys. Chem. Surf., 55, 603-607. DOI: 10.1134/S2070205119030031.

[10] Benhachem, F.-Z., Attar, T., Bouabdallah, F. (2019). Kinetic study of adsorption methylene blue dye from aqueous solutions using activated carbon from starch. Chem. Rev. Lett., 2, 33-39. DOI: 10.22034/CRL.2019.87964.

[11] Benhachem, F.-Z., Attar, T. (2019). Comparison studies for the removal of a basic dye from aqueous solution using coffee residues and waste tea. Inter. J. Adv. Chem., 7, 97-103. DOI: 10.14419/ijac.v7i1.29596.

[12] Shukla, S.K., Singh, A.K., Murulana, L.C., Kabanda, M.M., Ebenso, E.E. (2012). Inhibitive Effect of Azorubine Dye on the Corrosion of Mild Steel in Hydrochloric Acid Medium and Synergistic Iodide Additive. Int. J. Electrochem. Sci. 7, 5057-5068.

[13] Peme, T., Olasunkanmi, L.O., Bahadur, I., Adekunle, A.S., Kabanda, M.M., Ebenso, E.E. (2015). Adsorption and Corrosion Inhibition Studies of Some Selected Dyes as Corrosion Inhibitors for Mild Steel in Acidic Medium Gravimetric, Electrochemical, Quantum Chemical Studies and Synergistic Effect with Iodide Ions. Molecules., 20, 16004-16029.
DOI: 10.3390/molecules200916004.

[14] Abdeli, M., Ahmadi, N.P., Khosroshahi, R.A. (2010). Nile Blue and Indigo Carmine organic dyes as corrosion inhibitor of mild steel in hydrochloric acid. J. Solid. State. Electrochem., 14, 1317-1324. DOI: 10.1007/s10008009-0925-z.

[15] Al-Moubaraki, A.H. (2015). Corrosion Protection of Mild Steel in Acid Solutions Using Red Cabbage Dye. Chem. Eng. Commun., 202, 1069-1080. DOI: $10.1080 / 00986445.2014 .907565$.

[16] El-Boraei, N., Halim, S., Ibrahim, M. (2018). Effective corrosion inhibition of mild steel in acidic medium using inexpensive kermes natural dye: experimental and quantum chemical study. Anti-Corros. Method. M., 65, 626-636. DOI: 10.1108/ACMM-04-2018-1927.

[17] El Sayed, M.Y., Abdel-Gaber, A.M., Rahal, H.T. (2019). Safranin-A Potential Corrosion Inhibitor for Mild Steel in Acidic Media: A Combined Experimental and Theoretical Approach. J. Fail. Anal. Prev., 19, 1174-1180. DOI: $10.1007 / \mathrm{s} 11668-019-00719-6$.

[18] Oguzie, E.E., Onuoha, G.N., Onuchukwu, A.I. (2005). The inhibition of aluminium corrosion in potassium hydroxide by "Congo Red" dye, and synergistic action with halide ionsnull. Anti-Corros. Meth. Mater., 52, 293-298. DOI: $10.1108 / 00035590510615794$.

[19] Oguzie, E.E., Okolue, B.N., Ogukwe, C.E., Unaegbu, C. (2006). Corrosion inhibition and adsorption behaviour of bismark brown dye on aluminium in sodium hydroxide solution. Mater. Lett., 60, 3376-3378. DOI: 10.1016/j.matlet.2006.03.018.

[20] Oguzie, E.E., Akalezi, C.O., Enenebeaku, C.K., Aneke, J.N. (2010). Corrosion inhibition and adsorption behavior of malachite green dye on aluminum corrosion, Chem. Eng. Com$m u n$. , $\quad 198, \quad 46-60$. D O I : 10.1080/00986445.2010.493.

[21] Eduok, U., Inam, E., Umoren, S.A., Akpan, I.A. (2013). Chemical and spectrophotometric studies of naphthol dye as an inhibitor for aluminium alloy corrosion in binary alkaline medium. Geosystem. Engineering., 16, 146155. DOI: 10.1080/12269328.2013.803708.

[22] Li, X., Deng, S., Fu, H., Zhao, N., Li, Y., Mu, G. (2009). Corrosion inhibition of cresol red for cold rolled steel in phosphoric acid solution. Corros. Sci. Prot. Technol., 21, 354-357. DOI: 10.3969/j.issn.1002-6495.2009.04.002.

[23] Li, X., Deng, S., Fu, H. (2010). Inhibition effect of methyl violet on the corrosion of cold rolled steel in $1.0 \mathrm{M} \mathrm{HCl}$ solution. Corros. Sci. , $\quad 52, \quad 3413-3420$. D O I : 10.1016/j.corsci.2010.06.013. 
[24] Deng, S., Li, X., Fu, H. (2011). Alizarin violet $3 \mathrm{~B}$ as a novel corrosion inhibitor for steel in $\mathrm{HCl}, \mathrm{H}_{2} \mathrm{SO}_{4}$ solutions. Corros. Sci., 53, 35963602. DOI: 10.1016/j.corsci.2011.07.003.

[25] Zaferani, S.H., Shishesaz, M.R. (2014). Corrosion Inhibition of Carbon Steel in Acidic Solution by Alizarin Yellow GG (AYGG). J. Pet. Environ. Biotechnol., 5, 1-5. DOI: 10.4172/2157-7463.1000188

[26] Ebenso, E.E., Alemu, H., Umoren, S.A., Obot, I.B. (2008.) Inhibition of Carbon steel Corrosion in Sulphuric Acid Using Alizarin Yellow GG Dye and Synergistic Iodide Additive. Int $J$ Electrochem Sci., 3, 1325-1339.

[27] Onen, A.I., Maitera, O.N., Joseph, J., Ebenso, E.E. (2011). Corrosion inhibition potential and adsorption behaviour of bromophenol blue and thymol blue dyes on mild steel in acidic medium. Int. J. Electrochem Sc., 6, 2884-2897.

[28] El-Haddad, M.N., Fouda, A.S., Mostafa, H.A. (2013). Corrosion Inhibition of Carbon Steel by New Thiophene Azo Dye Derivatives in Acidic Solution. J. Materi. Eng. Perform., 22, 2277-2287. DOI: 10.1007/s11665013-0508-0.

[29] Valle-Quitana, J.C., Dominguez-Patiño, G.F., Gonzalez-Rodriguez, J.G. (2014). Corrosion Inhibition of Carbon Steel in $0.5 \mathrm{M} \mathrm{H}_{2} \mathrm{SO}_{4}$ by Phtalocyanine Blue. ISRN Corrosion., 2014, 1-8. DOI: $10.1155 / 2014 / 945645$

[30] Abd-El-raoufa, M., El-Azabawy, O.E., ElAzabawy, R.E. (2015). Investigation of adsorption and inhibitive effect of acid red GRE (183) dye on the corrosion of carbon steel in hydrochloric acid media. Egypt. J. Pet., 24, 233-239. DOI: 10.1016/j.ejpe.2015.07.006

[31] Attar, T., Larabi, L., Harek, Y. (2014). Inhibition effect of potassium iodide on the corrosion of carbon steel (XC 38) in acidic medium. Inter. J. Adv. Chem., 2, 139-142. DOI: 10.14419/ijac.v2i2.3272.

[32] Pearson, R. (1988). Absolute electronegativity and hardness: application to inorganic chemistry. Inorg. Chem., 27, 734-740. DOI: 10.1021/ic00277a030.

[33] Yuan, S., Liang, B., Zhao, Y., Pehkonen, S. (2013). Surface chemistry and corrosion behaviour of 304 stainless steel in simulated seawater containing inorganic sulphide and sulphate-reducing bacteria. Corros. Sci., 74, 353-366. DOI:10.1016/j.corsci.2013.04.058.

[34] Chygyrynets, E., Vorobyova, V. (2014). A Study of Rape-Cake Extract as Eco-Friendly Vapor Phase Corrosion Inhibitor. Chem. Chem. Technol., 8, 235-242. DOI: 10.23939/chcht08.02.235.
[35] Eddy, N.O., Ita, B.I. (2011). QSAR, DFT and quantum chemical studies on the inhibition potentials of some carbozones for the corrosion of mild steel in $\mathrm{HCl}$. J. Mol. Model., 17, 359-376. DOI:10.1007/s00894-010-0731-7.

[36] Samsonowicz, M., Regulska, E., Świsłocka, R., Butarewicz, A. (2018). Molecular structure and microbiological activity of alkali metal 3,4-dihydroxyphenylacetates. J. Saudi Chem. So c . , $\quad 22, \quad 896-907$. D O I : 10.1016/j.jscs.2018.01.0097.

[37] Attar, T., Messaoudi, B., Benhadria, N. (2020). DFT Theoretical Study of Some Thiosemicarbazide Derivatives with Copper. Chem. Chem. Technol., 14, 20-25. DOI: 10.23939/chcht14.01.020.

[38] Hassan, R.M., Zaafarany, I.A. (2013). Kinetics of corrosion inhibition of aluminium in acidic media by water-soluble natural polymeric pectates as anionic polyelectrolyte inhibitors. Materials., 6, 2436-2451. DOI: 10.3390/ma6062436.

[39] Anyiam, C.K., Ogbobe, O., Oguzie, E.E. (2020). Corrosion inhibition of galvanized steel in hydrochloric acid medium by a physically modified starch. Sn. Appl. Sci., 2, 520527. DOI: $10.1007 / \mathrm{s} 42452-020-2322-2$.

[40] Shahidi, Z.M., Golestani, G., Gholamhosseinzadeh, M. (2017). Mentha spicata L. Extract as a Green Corrosion Inhibitor for Carbon Steel in HCl Solution. Phys. Chem. Res., 5, 293-307. DOI: 10.22036/pcr.2017.41160.

[41] Benchadli, A., Attar, T., Choukchou-Braham E. (2019). Inhibition of Carbon Steel Corrosion in Perchloric Acid Solution by Povidone Iodine. Phys. Chem. Res., 7, 837-848. DOI: 10.22036/pcr.2019.198787.1665.

[42] Doner, A., Solmaz, R., Ozcan, M., Kardas, G. (2011). Experimental and Theoretical Studies of Thiazoles as Corrosion Inhibitors for Mild Steel in Sulphuric Acid Solution. Corros. Sci., $53, \quad 2902-2913$. D O I : 10.1016/j.corsci.2011.05.027.

[43] Chakravarthy, M.P., Mohana, K.N., Pradeep Kumar, C.B. (2014). Corrosion inhibition effect and adsorption behaviour of nicotinamide derivatives on mild steel in hydrochloric acid solution. Int. J. Ind. Chem., 5, 1-21. DOI: 10.1007/s40090-014-0019-3.

[44] Mobin, M., Zehra, S., Aslam, R. (2016). LPhenylalanine methyl ester hydrochloride as a green corrosion inhibitor for mild steel in hydrochloric acid solution and the effect of surfactant additive. $R S V$. Adv., 6, 5890-5902. DOI: $10.1039 / \mathrm{c} 5 \mathrm{ra} 24630 \mathrm{j}$.

[45] Khouri, S.J. (2015). Titrimetric study of the solubility and dissociation of benzoic acid in water: effect of ionic strength and tempera- 
ture. Am. J. Analyt. Chem., 6, 429-436. DOI: 10.4236/ajac.2015.65042.

[46] Al-Moghrabi, R.S., Abdel-Gaber, A.M., Rahal, H.T. (2018). A comparative study on the inhibitive effect of Crataegusoxyacantha and Prunusavium plant leaf extracts on the corrosion of mild steel in hydrochloric acid solution. Int. J. Ind. Chem., 9, 255-263. DOI: 10.1007/s40090-018-0154-3

[47] Abdel-Gaber, A.M., Rahal, H.T., Beqai, F.T. (2020). Eucalyptus leaf extract as a ecofriendly corrosion inhibitor for mild steel in sulfuric and phosphoric acid solutions. Int. J. Ind. Chem., 11, 1-10. DOI: 10.1007/s40090020-00207-z

[48] Lukovits, I., Kalman, E., Zucchi, F. (2001). Corrosion Inhibitors-Correlation between Electronic Structure and Efficiency. Corrosion., 57, 3-9. DOI: 10.5006/1.3290328.
[49] Murulana, L.C., Singh, A.K., Shukla, S.K., Kabanda, M.M., Ebenso, E.E. (2012). Experimental and quantum chemical studies of some bis (trifluoromethyl-sulfonyl) imide imidazolium-based ionic liquids as corrosion inhibitors for mild steel in hydrochloric acid solution. Ind. Eng. Chem. Res., 51, 13282 13299. DOI: 10.1021/ie300977d.

[50] Kaya, S., Tüzün, B., Kaya, C., Obot, I.B. (2016). Determination of corrosion inhibition effects of amino acids: Quantum chemical and molecular dynamic simulation study. J. Taiwan. Inst. Chem. E., 58, 528-535. DOI: 10.1016/j.jtice.2015.06.009.

[51] Zhang, P., Xu, D., Li, Y., Yang, K., Gu, T. (2015). Electron mediators accelerate the microbiologically influenced corrosion of 304 stainless steel by the Desulfovibrio vulgaris biofilm. Bioelectrochemistry., 101, 14-21. DOI: 10.1016/j.bioelechem.2014.06.010. 